\title{
A Review on Role of Nanoparticles and Active Compounds of Ocimum and Azadirahcta in Water Purification and Therapeutics
}

\author{
Noor Nihad Abdul Hussein
}

Department of Clinical Laboratory Science, College of Pharmacy, University of Baghdad, Baghdad, Iraq. Email:noor.n.ameen@gmail.com

\author{
Received: 22nd February 2020, Accepted: 13th March 2020, Published: 30th April 2020
}

\begin{abstract}
Water being the universal solvent and one of the first essential requirements of any life, demands an utmost care and attention for maintaining its quality and quantity on earth. Due to a high increase in the pollution rate and use of non bio-degradable substances, the water resources are contaminated day by day. It is very essential to purify the water not only from its physical impurities but also from its biological impurities and retain its nutritional quality. The current review focuses on the importance of various water purification techniques and the use of herbal extracts in the purification and quality enhancement of potable water. The review also highlights various herbs and Plants with medicinal values that can be used in water purification techniques.
\end{abstract}

\section{Keywords}

Ocimum, Azadirachta, Nanoparticles, Water Purification, Therapeutics

\section{Introduction}

Maintaining the quality of the water is not an optional concept but a must to be followed step before using it for various household purposes. Use of contaminated and polluted water could lead to several water borne diseases and infections like Cholera, Typhoid, diarrhea, dysentery etc. It is not only important to remove pathogenic agents from water but maintaining the nutritional and mineral quality of water is also necessary. Lack of water minerals may lead to nutrition deficiencies and dental problems. Thus it is important to take utmost care in the purification and mineralization of water before being sent for household consumption.

Several techniques for the water purification are known since long like chlorination, filtration, sedimentation, distillation etc. Though these techniques are capable of removing particulate impurities and microbial contaminants, but it could not be related to the retention or enhancement of mineral content of water. Thus a new technique of water purification and mineralization is the use of herbs and their extracts. Many studies have proven the role of several medicinal plants like Azadirachta, Ocimum, Phyllanthus, Moringa etc in water purification.

\footnotetext{
Application of Nano Technology in Water Purification

Nano technology is the current most advanced technology wherein micro concentrations of elements are proved to be working at the macro scales for several problems. Use of micro or nanoparticles in several areas especially in therapy has gained its importance.

Charusheela Ramteke et.al, have focused on synthesis of Silver nanoparticles (17) from the aqueous extract of leaves of Ocimum sanctum for enhanced antibacterial activity. The article reports the synthesis of Silver nanoparticles using leaf broth of Ocimum sanctum. These particles were characterized by Transmission electron Microscopy, X ray diffractometry, UV Spectrophotometry etc. The extract was found to contain significant amounts of reducing entities in it. These nanoparticles proved to be well efficient in acting against the well known pathogens like S. aureus and $\mathrm{E}$ coli.

Sonali Priyadarshini and team from Orissa Agricultural University $(18,19)$ had conducted a study on Green Synthesis of Silver Nanoparticles using Azadirachta Indica and Ocimum Sanctum Leaf Extract wherein the authors have tested the antimicrobial activity of both Azadirachta and Ocimum against bacteria causing UTI infection like $E$ coli, Klebsiella pneumonia and $S$ aureus using Disc diffusion method. Silver Nanoparticles from Ocimum proved to be efficient with zone of $12.00 \pm 0.65 \mathrm{~mm}$ for E coli, $9.66 \pm 0.11 \mathrm{~mm}$ for $\mathrm{K}$ pneumonia and $\mathrm{S}$ aureus was inhibited to $23.00 \pm 0.81 \mathrm{~mm}$ at $1 \mathrm{mg} / \mathrm{ml}$ concentrations. The data obtained for silver nanoparticles form Azadirachta leaf extract were $9.11 \pm 0.81 \mathrm{~mm}$ for $\mathrm{K}$ pneumoniae and $09.0 \pm 1.17$ for $\mathrm{S}$ aureus. Thus both of them can be used in the disinfection of drinking water.

Priya Bannergee et.al from University of Calcutta (20) have governed a leaf extract mediated green synthesis of silver nanoparticles from widely available Indian plants wherein the synthesis, characterization, antimicrobial property and toxicity analysis was performed. They dealt with the application of nanotechnology for producing the silver nanoparticles from herbs. The study involved and economic protocol or the production of silver nanoparticles using
} 
$1 \mathrm{mM}$ Silver Nitrate and aqueous extracts of 3 different herbs Musa balbisiana (banana), Azadirachta indica (Azadirachta) and Ocimum tenuiflorum (black Ocimum). A good degree of antimicrobial activity was shown by Silver nanoparticles with herbal extracts against E coli and Bacillus sp. compared to individual extracts and simple silver nitrate.

\section{Therapeutic Compounds in Azadirachta}

Mohammad A. Alzohairy from College of Applied Medical Sciences, Quassim University in 2016 conducted a research on the chemical components of Azadirachta responsible for its therapeutic role. In the study it was stated that the plant is used in Unani, Ayurveda, and Chinese medicine and also in the treatment of several diseases and ailments. The article also suggests about the anticancer activity of the herbal plant. Some of the important chemical components imparting its therapeutic potential are: azadirachtin, nimbolinin, nimbin, nimbidin, nimbidol, sodium nimbinate, gedunin, salannin, and quercetin. The leaves of this tree contain nimbin, nimbanene, 6-desacetylnimbinene, nimbandiol, nimbolide, ascorbic acid, n-hexacosanol and amino acid, 7-desacetyl-7-benzoylazadiradione, 7desacetyl-7-benzoylgedunin, 17-hydroxyazadiradione, and nimbiol (4) Some of the other important therapeutic components in Azadirachta include Quercetin, polyphenolic flavonoids.

Genetic level study was also conducted on the anti cancer effect of Azadirachta extract. It was found that the ethanolic extract of Azadirachta leaf upregulates the pro apoptotic genes and proteins which include P53, Bax (Bcl-2-associated $\mathrm{X}$ protein), (Bcl-2-associated death promoter protein) Bad etc. One of the study revealed that ethanolic Azadirachta leaf extract enhanced the expression of certain proapoptotic genes like caspase- 8 and caspase- 3 , and also suppresses the expression of Bcl-2 and mutant p53. All these cellular activities indicate that Azadirachta extracts can be used for the prevention of infections and also for the therapy of various diseases.

\section{Mechanism of Action}

The therapeutic effect is provided by several mechanisms like:

Free radical activation, Cell signaling pathway regulation, Enzyme Activity regulation.

The herb being a rich source of antioxidants possesses the property of free radical scavenging thereby causing the lysis or death of pathogenic agents and cells. Azadirachta exhibits a peculiar activity on Oncogenes, Tumor suppressor gene. It has a role in angiogenesis, Apoptosis etc.

Paola Del Serrone (2015) et al detailed about the efficiency of Azadirachta extracts against enteropathogens causing intestinal diseases. They explained the pathogenic activity of Azadirachta extracts specifically against $\mathrm{E}$ coli involved in various intestinal infections and also a major pollutant in water. 48 different isolates of $\mathrm{E}$ coli were tested against the Azadirachta extract (5). A study revealed that the treatment of Azadirachta oil causes a decline in the cell count of E coli due to cell death.

\section{Important Components in Ocimum with Therapeutic Role}

One of the articles in "India water portal" by Aditi sharma (May 2014) focused on the therapeutic role of Ocimum where Ocimum is referred as the purifier and reverse osmosis filter. The article states that a handful of Ocimum leaves have the capacity to detoxify 20 liters of water.

Table 1: Important Chemical Components in Ocimum and Azadirachta

\begin{tabular}{|c|c|}
\hline Ocimum & Azadiracta \\
\hline $\begin{array}{l}\text { Phenolic compounds (antioxidants) like cirsilineol, } \\
\text { circimaritin, isothymusin, apigenin rosameric acid, and } \\
\text { appreciable quantities of eugeno. } \\
\text { The oil also contains carvacrol and sesquiterpine } \\
\text { hydrocarbon caryophyllene } \\
\text { Two flavonoids Orientin and Andvicenin }\end{array}$ & $\begin{array}{l}\text { leaf extract: isomeldenin, nimbin, nimbinene, 6- } \\
\text { desacetyllnimbinene, nimbandiol, immobile, } \\
\text { nimocinol, quercetin, and beta-sitosterol. Two } \\
\text { additional tetracyclic triterpenoids zafaral } \\
\text { [24,25,26,27-tetranorapotirucalla-(apoeupha)-6alpha- } \\
\text { methoxy-7alpha-acetoxy-1,14-dien-3,16-dione-21-al] } \\
\text { and meliacinanhydride [24,25,26,27- } \\
\text { tetranorapotirucalla-(apoeupha)-6alpha- } \\
\text { hydroxy,11alpha-methoxy-7alpha,12alpha- } \\
\text { diacetoxy,1,14,20(22)-trien-3-one] } \\
\text { Seed: Azadirachtin H and Azadirachtin I } \\
\text { Tree Bark: Tannin, Oil }\end{array}$ \\
\hline
\end{tabular}


Pavithra Sivaraja (Jan 2012) have highlighted the importance of Ocimum in water purification (6). Their article reports that ocimum is not only antimicrobial but also plays a major role as anticancer, anti-diabetic and anti-ulcer activity. A research was conducted to assay the water purification efficacy of Ocimum on tap water and river water. The 500 $\mathrm{mg} /$ litre of extract treated water showed 95 to $98 \%$ antibacterial activity in 14 to $16 \mathrm{hrs}$.

Another study by Hanaa A. Yamani et.al (May 2016) reported the antimicrobial efficacy of the essential oils obtained from Ocimum tenuiflorum. At a concentration of 4.5 and $2.25 \%$ these oils inhibited the growth of $\mathrm{E}$ coli and $\mathrm{S}$ aureus including Methicillin resistant $\mathrm{S}$ aureus. A total of 54 compounds have been extracted from Ocimum possessing therapeutic effects. Of these compounds 3 major components include camphor, eucalyptol and eugenol. Some of the volatile compounds that were extracted from Ocimum using HS-SPME/GC-MS include Methyl isovalerate, Ethyl isovalerate, Tricyclene, Thujene, Alpha pinene, Camphene, Sabinene, Beta pinene, Octen 3 ol, Myrcene, Phellandrene, Terpinene etc., Due to the presence of such cytoactive compounds Ocimum exhibits bacteriostatic activity.

An article in Times of India (June 2017) published by Shivangani Dhavan emphasized (7) the medical benefits of Ocimum. The articles states that Ocimum has been used since generations in ayurvedic medications in view of its healing properties. Respiratory diseases can be treated using the leaf extracts of Basil. Several health issues like Kidney stones, Stress, Digestive disorders, Headache etc., can be treated by this magical plant. One of the best effects required for the current generation is its anti-diabetic effect by means of activation of Insulin releasing cells. Use of Basil root powder in water would control the sugar concentrations in the blood. It acts as a very good appetizer by acting upon the digestive enzymes and enhancing their secretions.

In recent times an article of Patanjali's Acharya Balkrishan (Nov 2017) (8) described Basil to be the "Queen of Herbs" with a natural efficacy to treat several diseases. It is referred as a virtual tonic for our body and health. Acharya Balakrishan states that the magical herb also has a potential to increase the expectancy of the life. Some of the metabolic effects of Ocimum are its Antibacterial, Antifungal, Anti-inflammatory and Antioxidant properties. It is known to be a natural remedy for several viral infections and acts in strengthening immunity, reproductive system, and cardiovascular system. It also has a healing effect on Skin and hair.

Surprisingly the leaf extract is also useful in the treatment of snake bites as per Abhijit Dey et.al, (2012).(9)

\section{Use of Azadirachta and Ocimum in the Water Treatment}

Based on the above mentioned potential of Azadirachta and Ocimum, several water purification techniques were designed which can yield good quality of portable water in a cost effective method. Some of the water purification practices followed including these extracts is mentioned below:

One such technique was proposed especially for people in rural areas who lack access of pure and safe drinking water because of open water channels. The lack of purification units lays the basis for the use of such techniques. One of the study conducted by Parthiban L et.al from VIT Tamil Nadu, March 2017 exposed the antimicrobial effect and purifying efficiency of Azadirachta and Ocimum seed extracts(1). Their work involved the use of these extracts for the treatment of water to impart purity and disinfect the water. The organisms that were found in the untreated water were Staphylococcus aureus, Bacillus, Jantheno, Chromobacteria, Dugenella and Streptococcus. All of these organisms showed susceptibility to the slurry of Azadirachta and Ocimum seed paste making water free from these pathogens. Thus the study proves the efficiency of these extracts in water purification.

According to an article by Pradeep Muttagadur et.al, both Ocimum and Azadirachta extracts can act against Enterococcus faecalis in Endodontics. This study showed that the leaf extracts were more effective against $E$. faecalis compared to $2 \%$ chlorhexidine gluconate (2). This depicts the importance of these herbs in preventing dental infections and plaque.

Tanushree Bhattacharjee et.al, (Jan 2013) conducted their study on the role of natural herbs in the disinfection of drinking water in rural areas. In their study the water from various sources was collected and treated with herbal extracts and the efficiency was tested by MPN indexing. The results showed that extract of Azadirachta reduced the MPN of water from well, lake and river from 313, 175 and 125 to 0,4 and 2, while Ocimum alcoholic extract reduced it to 2, 2 and 2 respectively (3). Thus the results conclude that both the herbs are efficient water purifying agents. Furthermore it is virtually the cheapest way to render contaminated water fit for human consumption.

In one of the articles of Robert Matthews and Dr M Templeton, uses of Azadirachta in the purification and disinfection of water was described. $(15,16)$ The study focused the region of Nepal as the economic status of the country is low and this can be an economic protocol for the disinfection of Drinking water. The major focus aspects of the work were: 
- To assess the antibacterial activity of Azadirachta oil and dried Azadirachta leaves against a contaminated surface water.

- To assess the performance of different forms in which the Azadirachta products can be applied to the water

- To assess the effectiveness of the most promising Azadirachta products against isolated E. coli

The results of the work revealed that the use of Azadirachta oil has considerably decreased the count of the Coli forms in the sample; however the faecal coliforms were not inhibited by the oil.

Mr. Chandy Abraham, Kottayam, Kerala has published his practice on the use of these magical herbs in water purification (10). He has used the simplest method of just adding a fistful of both the leaves in the sample water to be purified and mixed. The container was kept aside without disturbing for 4 to $5 \mathrm{hrs}$. The extract was purified and water was collected. The results showed pure and contamination free water but with a lite aroma and bitter taste. However the protocol can be employed in those situations where the sterilized water supply is difficult.

Ashwini Yevate et.al, dealt with development of a simple water purification unit based on the Ocimum and Azadirachta leaf extract (11) especially used for the removal of fluorine from water containing high fluoride content. The setup included the clay made pot into which a candle and a disc made of the Azadirachta and Ocimum extracts were inserted. The water to be purified was allowed to pass through the container. To analyze the quality of water the fluoride concentration was estimated before and after the treatment. The results conclude that the average $\%$ removal of fluoride from water was around $51.35 \% \& 47.77 \%$ using Ocimum \& Azadirachta powder respectively (12). Thus it can be a basis for the development of further sophisticated mechanisms.

Aniruddha Bhalchandra Pandit (March 2019) proved that the treatment of water for drinking using Ocimum and Azadirachta leaf extracts was very satisfactory. $500 \mathrm{mg} /$ litre of Ocimum extract treated water showed 95 to $98 \%$ antibacterial activity in 14 to $16 \mathrm{hrs}$ as proved by plate count assay (13). The study also showed that the alcoholic extracts of Azadirachta and Ocimum exhibited a high reduction in the MPN number and specifically exhibited an inhibitory effect against Salmonella typhi, involved in the onset of Typhoid.

This concludes that the use of these herb treated water can protect against several coliform infections and also prevent typhoid.

\section{Conclusion}

In view of the importance of water treatment in preventing the water borne diseases, the current review focuses on the use of Ocimum and Azadirachta extracts as well as their nanoparticles in the water treatment and purification. Several Research articles, books and papers were mined and reviewed to analyze the importance of these two herbs in preventing the pathogenic organisms. The chemical components within these herbs, was dealt and their importance is explained. Several techniques involving the use of these herbs are mentioned. The medicinal, therapeutic and purifying efficacy of these two leaf extracts was emphasized. The study concludes that both the plants are magical herbs possessing antibacterial, antifungal and anti-inflammatory nature. The have the potential to prevent the growth of pathogens like Salmonella staphylococcus, E coli etc. Use of these extracts as the source of water purification will not only eliminate the pathogenic bacteria and other organisms but also enhances the biological quality of water by imparting it some herbal properties. Additionally the extracts can be complexed with silver nanoparticles to increase their efficacy and functionality. The article also illustrated several research articles which proved the efficacy of silver nanoparticles in fusion with the herbal leaf extracts for the purification of drinking water. These extracts are known to inhibit the growth of several intestinal pathogenic bacteria like E coli, Klebsiella, $\mathrm{S}$ aureus etc. Thus, this technique has to be emphasized and focused to build up economic and simple water purification units. This would be of importance in villages where the supply of pure and unpolluted water is a challenging task.

\section{References}

1. Parthiban L et.al.," Clarification and Disinfection of Water Using Natural Herbs (Azadirachta and Ocimum) Azadirachta Indica and Ocimum Sanctum", Journal of Chemical and Pharmaceutical Sciences, Volume 10, Issue 1 March 2017

2. Pradeep Muttagadur Chandrappa et.al., "Antimicrobial activity of herbal medicines (Ocimum extract, Azadirachta extract) and chlorhexidine against Enterococcus faecalis in Endodontics: An in vitro study", Journal of International Society of Preventive and Community Dentistry", 2015 Dec; 5(Suppl 2): S89-S92, PMID: 26942123

3. https://www.researchgate.net/publication/265513540_Disinfection_of_Drinking_Water_in_Rural_Area_Us ing_Natural_Herbs 
4. Mohammad A. Alzohairy, "Therapeutics Role of Azadirachta indica (Azadirachta) and Their Active Constituents in Diseases Prevention and Treatment", Evidence based Complementary and Alternative Medicine, 2016 Mar, PMID: 27034694

5. Paola Del Serrone et.al., "Azadirachta (Azadirachta indica A. Juss) Oil to Tackle Enteropathogenic Escherichia coli", BioMed Research International, Special Issue: Antibiotic Resistance of Bacteria, Volume 2015 |Article ID 343610

6. Pavithra Sivaraja,"Effect of Ocimum (Ocimum sanctum) as a Disinfectant for Water Treatment", Research Gate, January 2012

7. https://timesofindia.indiatimes.com/life-style/health-fitness/diet/benefits-ofOcimum/articleshow/32719691.cms?from=mdr

8. https://www.asianage.com/life/health/261117/queen-of-herbs-Ocimum-the-natural-cure-for-most-diseasessays-patanjalis-acharya-bal-krishan.html

9. Abhijit Dey et.al, "Traditional Use of Plants Against Snakebite in Indian Subcontinent: A Review of the Recent Literature", AJTCAM, 2012; 9(1): 153-174, PMID: 23983332

10. Mr. Chandy Abraham, Kottayam, Kerala, "Purifying water using Azadirachta and Ocimum

11. http://ethesis.nitrkl.ac.in/6113/1/110CE0503-3.pdf

12. Ashwini Yevate ET., "Low Cost Water Purifier By Using Natural Herbs", IJSART - Volume 3 Issue 9 SEPTEMBER 2017

13. https://pubs.rsc.org/en/content/ebook/978-1-78801-019-1

14. Sunita Verma et.al., "Chemical constituents and pharmacological action of Ocimum sanctum (Indian holy basil-Ocimum)", The Journal of Pharmacology, 2016; 5(5): 205-207, Sep 2016

15. https://www.imperial.ac.uk/pls/portallive/docs/1/49977696.PDF

16. Rajesh R. Wankhade "Role of some Natural Herbs in Water Purification", IOSR Journal of Applied Chemistry, Volume 9, Issue 3 Ver. I (Mar. 2016)

17. Charusheela Ramteke, "Synthesis of Silver Nanoparticles from the Aqueous Extract of Leaves of Ocimum sanctum for Enhanced Antibacterial Activity", Hindawi, Journal of Chemistry, Article ID 278925, Volume 2013

18. Sonali Priyadarshini et.al., "Green Synthesis of Silver Nanoparticles using Azadirachta Indica and Ocimum Sanctum Leaf Extract" Current Science, Volume 117, Oct 2019

19. Feng, Q. L., Wu, J., Chen, G. Q., Cui, F. Z., Kim, T. N. and Kim, J. O., A mechanistic study of the antibacterial effect of silver ions on Escherichia coli and Staphylococcus aureus. J. Biomed. Mater. Res., 2000, 52, 662-668

20. Banerjee, P., Satapathy, M., Mukhopahayay, A. et al. Leaf extract mediated green synthesis of silver nanoparticles from widely available Indian plants: synthesis, characterization, antimicrobial property and toxicity analysis. Bioresour. Bioprocess. 1, 3 (2014). 